\title{
Venous thromboembolism: Prophylactic and therapeutic practice guideline
}

\author{
B F Jacobson, S Louw, H Büller, M Mer, P R de Jong, P Rowji , E Schapkaitz, D Adler, A Beeton, H-C Hsu, P Wessels, S Haas, \\ on behalf of the Southern African Society of Thrombosis and Haemostasis
}

Department of Molecular Medicine and Haematology, University of the Witwatersrand and National Health Laboratory Services, Johannesburg, South Africa

B F Jacobson, MB ChB, FRCS (Glasg), MMed (Haematol), FCPath (SA), PhD (Med)

S Louw, MB BCh, FCPath (Haem), MMed (Haem)

E Schapkaitz, MB BCh, FCPath (Haem), MMed (Haem)

Department of Vascular Medicine, Academic Medical Center, Amsterdam, The Netherlands

$\mathrm{H}$ Büller, $\mathrm{MD}, \mathrm{PhD}$

Department of Medicine, Division of Pulmonology and Critical Care, Charlotte Maxeke Johannesburg Academic Hospital and University of the Witwatersrand, Johannesburg, South Africa

M Mer, MB BCh, Dip PEC (SA), FCP (SA), MMed (Int Med) Pulmonol, Cert Crit Care (SA), FRCP (Lond), FCCP, PhD

Department of Obstetrics and Gynaecology, University of Cape Town, and Chris Barnard Memorial Hospital, Cape Town, South Africa

P R de Jong, FRCOG, FCOG, MMed

Neurology Association of South Africa

P Rowji, BSc, BSc Hons, MB BCh, FCP Neurol (SA)

Faculty of Consulting Physicians, South Africa

D Adler, BSc (Med), MB BCh, FCP (SA)

Wits Donald Gordon Medical Centre, Johannesburg, South Africa

A Beeton, MB BCh, DA (SA), FFA (SA)

Milpark Hospital, Johannesburg, and Executive Member, South African Renal Consortium, South Africa

$\mathrm{H}-\mathrm{C} \mathrm{Hsu}, \mathrm{MB} \mathrm{BCh}, \mathrm{FCP}$ (SA)

Consultant, Ampath Laboratories, and Consultant, Department of Medical Oncology, University of Pretoria, South Africa

P Wessels, MB ChB, MMed (Haematol), Cert Clin Haematol (CMSA)

Technical University of Munich, Germany

S Haas, MD

Corresponding author: SLouw (susan.louw@nhls.ac.za)

Background. Pharmacological prophylactic anticoagulation in many countries, including South Africa, is under-prescribed. This has resulted in unacceptable rates of morbidity and mortality.

Method. The Southern African Society of Thrombosis and Haemostasis held a meeting to update the previous guideline and review new literature including guidelines from other societies. The following specialties were represented on the committees: anaesthetics, cardiology, clinical haematology, critical care, obstetrics and gynaecology, haematopathology, internal medicine, neurology, orthopaedic surgery and pulmonology. A draft document was presented at the meeting, which was then revised by consensus agreement. To avoid local bias, the guideline was adjudicated by recognised international external experts.

Results and conclusion. A concise, practical updated guideline for thromboprophylaxis and treatment in medical and surgical patients has been produced for South African conditions. It is hoped that this guideline will continue to improve anticoagulation practice in this country, which we believe will directly benefit patient outcomes.

S Afr Med J 2013;103(4):260-267. DOI:10.7196/SAMJ.6706

\section{Prophylactic anticoagulation}

This guideline reflects current best practice. However, every patient should still be assessed on merit, with individualisation of therapy where indicated. Special attention is needed in geriatric and obese patients, those with renal dysfunction and those with concomitant medical disorders. Drug recommendations are based on Medicines 
Control Council (MCC) registration at the time of publication, unless otherwise indicated.

\subsection{Medical patients ${ }^{[1-7]}$ \\ 1.1.1 Background}

In the absence of anticoagulation, the risk of deep-vein thrombosis (DVT) in medically ill patients is comparable to that in moderaterisk surgical patients $(10-20 \%)$. Although the clinical significance of asymptomatic distal DVT is debatable, pulmonary embolism (PE) is the commonest preventable cause of death in hospital patients, contributing to $10 \%$ of all hospital deaths. Three-quarters of these deaths occur in medically ill patients. The efficacy of heparins in preventing venous thromboembolism (VTE) in medically ill patients is now well established. However, their use is associated with a modestly increased risk of major bleeding episodes, and this should be balanced against the thrombotic risk.

\subsubsection{Risk assessment}

Risk assessment is essential, and treatment needs to be individualised. Refer to Appendix I for further information.

\subsubsection{Recommendations for prophylaxis in medically ill patients} NOTE: Aspirin offers only weak VTE prophylaxis when compared with other agents used for prophylaxis such as low-molecularweight heparin (LMWH).

The recommended prophylactic doses for LMWH and unfractionated heparins are as follows:

- enoxaparin $40 \mathrm{mg}$ (4 000 anti-Xa units) sc (subcutaneously) daily OR

- unfractionated heparin (UFH) $5000 \mathrm{U}$ sc tds (three times per day).

Evidence-based data show LMWH to be superior to UFH.

LMWH should be given to all bedridden medically ill patients who have:

- conditions associated with a high risk of thrombosis (see Appendix I)

OR

- other medical conditions (such as acute infections or acute rheumatic disease) with at least one associated risk factor.

NOTE: Prophylaxis is not required for patients who are mobile, i.e. when more active than sitting in a chair and walking to the bathroom.

In patients at high risk of bleeding, the use of mechanical prophylaxis such as graduated compression stockings or intermittent pneumatic compression (IPC) should be considered as an alternative if the risk of thrombosis is high.

\subsubsection{Monitoring}

See 'General recommendations', section 1.2.6.

\subsection{Surgical patients ${ }^{[8-14]}$ \\ 1.2.1 Background}

Refer to comments in sections 1.1.1 and 1.1.2 regarding background and risk assessment. VTE is an important cause of morbidity and mortality in surgical patients. However, the relative risk of developing VTE varies, and some measure of risk assessment is required for appropriate selection of prophylaxis. This guideline attempts to simplify risk assessment models, which are often too complicated for routine use.

Both patient-related and procedure-related risk factors should be considered when assessing an individual's risk of developing VTE.
Table 1. DVT prevalence in various patient populations

\begin{tabular}{ll}
\hline Patient information & $\begin{array}{l}\text { DVT prevalence } \\
\text { \% }\end{array}$ \\
\hline Internal medicine & $10-20$ \\
General surgery & $15-40$ \\
Major gynaecological surgery & $15-40$ \\
Major urological surgery & $15-40$ \\
Neurosurgery & $15-40$ \\
Stroke & $15-40$ \\
Hip and knee replacement surgery & $40-60$ \\
Hip fractures & $40-60$ \\
Polytrauma & $40-80$ \\
Spinal cord injury & $60-80$ \\
Critical care & $10-80$
\end{tabular}

\subsubsection{Patient-related risk factors}

- age $>60$ years

- history of VTE

- immobility

- underlying malignancies

- pregnancy

- oestrogen therapy

- obesity

- hereditary thrombophilic state

- inflammatory bowel disease

- HIV/AIDS

- auto-immune diseases including antiphospholipid syndrome.

\subsubsection{Procedure-related risk factors}

- duration of the procedure

- degree of tissue damage (orthopaedic/trauma surgery carries the greatest risk)

- degree of immobility following surgery

- nature of the surgical procedure (e.g. lower limb orthopaedic surgery, neurosurgery, etc.).

1.2.2 Recommendations for prophylaxis in surgical patients NOTE: Aspirin offers only weak VTE prophylaxis when compared with other agents used for prophylaxis such as LMWH.

1.2.2.1 Low-risk procedures (minor surgery) with no patientrelated risk factors

- No specific prophylaxis is required.

- Early mobilisation is recommended.

1.2.2.2 Higher-risk procedures (major surgery) with no patientrelated risk factors OR low-risk procedures with additional patient-related risk factors

- Enoxaparin 40 mg (4 000 anti-Xa units) sc daily

OR

- Dalteparin $0.2 \mathrm{ml}$ (2 500 anti-Xa units) sc daily

OR

- Nadroparin:

- Abdominal surgery: $0.3 \mathrm{ml}$ (2 850 anti-Xa units) sc 2 hours pre-operatively and 8 hours after surgery, followed by $0.3 \mathrm{ml}$ daily for 7 days 
- Knee and hip replacement surgery: weight-adjusted dose of 38 anti-Xa units/kg sc 12 hours pre-operatively and repeated 12 hours after surgery is completed and daily on days $1-3$, with 57 anti-Xa units/kg sc from day 4 for a minimum of 10 days.

Prophylaxis can be given 12 hours before surgery. Postoperative administration is acceptable, and then once daily thereafter (see 'Timing of prophylaxis', section 1.2.3).

IPC devices may be acceptable alternatives, particularly if minor bleeding is likely to be harmful or other factors suggest an increased bleeding risk. If feasible and practical, IPC devices can therefore be utilised, although at most only modest evidence exists as to their benefit.

1.2.2.3 Higher-risk procedures (major surgery) with additional patient-related risk factors $O R$ very high-risk procedures (orthopaedic or trauma surgery)

- Enoxaparin 40 mg (4 000 anti-Xa units ) sc daily

OR

- Dalteparin $0.4 \mathrm{ml}$ (5 000 anti-Xa) units sc daily

OR

- Nadroparin:

- Abdominal surgery: $0.3 \mathrm{ml}$ (2 850 anti-Xa units) sc 2 hours pre-operatively and 8 hours after surgery, followed by $0.3 \mathrm{ml}$ daily for 7 days

- Knee and hip replacement surgery: weight-adjusted dose of 38 anti-Xa units/kg sc 12 hours pre-operatively and repeated 12 hours after end of surgery and daily on days $1-3$, with 57 OR anti-Xa units/kg sc daily from day 4 for a minimum of 10 days

- Dabigatran (only registered for prophylaxis in total hip and knee replacement):

- $110 \mathrm{mg}$ starting 4 hours after surgery and $220 \mathrm{mg}$ daily thereafter

- $75 \mathrm{mg}$ starting 4 hours after surgery and $150 \mathrm{mg}$ daily thereafter in special populations including: (i) moderate renal impairment (creatinine clearance $30-50 \mathrm{ml} / \mathrm{min}$ ); (ii) patients on amiodarone; and (iii) elderly patients

OR

- Rivaroxaban (only registered for prophylaxis in total hip and knee replacement):

OR

- 10 mg daily starting 6 hours after surgery

- Fondaparinux $2.5 \mathrm{mg}$ sc daily (only registered for prophylaxis in total hip and knee replacement surgery and only to be administered after surgery).

In this group of patients, use of additional mechanical devices such as IPC devices should be considered.

\subsubsection{Timing of prophylaxis}

NOTE: This is extremely controversial.

- Data are available confirming the benefits of prophylactic anticoagulation initiated pre-operatively.

- Although pre-operative initiation of prophylactic anticoagulation is desirable, there are data indicating that starting prophylaxis postoperatively is adequate. It should be given postoperatively within $6-12$ hours, i.e. NOT before 6 hours postoperatively and NOT after 12 hours postoperatively, provided no active bleeding is present. For major hip and knee surgery, a postoperative initiation time of 12 hours appears to be optimal.

- Adjustment of the dose in patients with renal failure is mandatory (refer to package inserts of individual drugs).
- The first dose of fondaparinux should always be given a minimum of 6 - 8 hours postoperatively.

- The new oral anticoagulants (NOACs) must only be given postoperatively, dabigatran 4 hours and rivaroxaban 6 hours after surgery.

- In patients at high risk of bleeding or undergoing neuroaxial anaesthesia (see separate recommendation below, section 1.2.5.1), anticoagulation should always only be initiated a minimum of 12 hours postoperatively.

\subsubsection{Duration of prophylaxis}

- General recommendations:

- major cancer surgery: 5 weeks

- hip replacement surgery: 5 weeks

- knee replacement surgery: 2 weeks.

- LMWH prophylaxis should be continued until patient is fully mobile.

- For major surgery in patients with additional risk factors or very high-risk procedures (major orthopaedic surgery), at least 7 - 10 days' prophylaxis is indicated.

- Extended out-of-hospital prophylaxis (up to 1 month) with LMWH or warfarin started immediately postoperatively, and adjusted to maintain an international normalised ratio (INR) of $2-3$, has been shown to provide additional benefit.

\subsubsection{Special circumstances}

1.2.5.1 Recommendations with reference to centroneuroaxial blockade (spinal and epidural anaesthesia) in the setting of prophylactic doses

- Neurological monitoring is mandatory for a minimum of 12 hours and ideally for 72 hours after neuroaxial blockade in association with anticoagulation.

- Extreme caution should be exercised in patients on other haemostatically active agents such as aspirin and non-steroidal anti-inflammatory agents.

- LMWH:

- Catheter should not be placed or removed within 12 hours following a dose of LMWH.

- LMWH should not be commenced less than 2 hours after insertion or removal of a neuroaxial catheter.

- LMWH should be delayed for at least 24 hours if there is blood in the needle or neuroaxial catheter during needle insertion.

- Fondaparinux:

- NOTE: only limited data are available and the committee is therefore unable to make definitive recommendations for this drug. Because of its long half-life, catheter removal should not take place earlier than 36 hours after cessation of fondaparinux.

- NOACs, rivaroxaban and dabigatran:

- Epidural catheter removal: 22 - 26 hours after last administration of a NOAC.

- After catheter removal: (i) the next rivaroxaban dose should be administered not earlier than 6 hours after removal; (ii) the next dabigatran dose should be administered not earlier than 1 hour after removal.

1.2.5.2 Recommendations with reference to thromboprophylaxis in pregnancy and gynaecological surgery

There are no drugs registered for this indication in pregnancy; these are therefore off-label recommendations. (All other recommendations in this guideline are as per registered indications/'on-label'.) 
Refer to Appendix I for VTE risk factor assessment.

- Thromboprophylaxis during pregnancy and after caesarean section $(\mathrm{CS})$ :

- Enoxaparin (LMWH) use during pregnancy is 'off-label', but is probably safe where benefit exceeds risk, i.e. in patients with VTE.

- Thromboprophylaxis after CS in healthy women with no VTE risk factors: early mobilisation and non-pharmacological methods (i.e. IPC).

- Thromboprophylaxis after CS in women with VTE risk factors (refer to Appendix I): (i) LMWH, e.g. enoxaparin $0.5 \mathrm{mg} / \mathrm{kg} \mathrm{sc} 12$ hours after CS provided there is no excessive active bleeding, and continued for 4 - 6 weeks after discharge (40 $\mathrm{mg}$ in patients of normal weight, $60 \mathrm{mg}$ in obese patients (body mass index (BMI) >35)); (ii) non-pharmacological methods can be added until discharge.

- NOACs (rivaroxaban and dabigatran) should not be used in pregnancy, as the molecules are small and cross the placenta, and should also be avoided while the mother is breastfeeding.

- Thromboprophylaxis following gynaecological surgery:

- Minor procedures in healthy women with no patient-related VTE risk factors: early mobilisation.

- Major procedures: (i) healthy women with no patient-related risk factors for VTE: LMWH, e.g. enoxaparin, $0.5 \mathrm{mg} / \mathrm{kg}$ (e.g. $40 \mathrm{mg}$ ) sc daily until discharge, beginning $6-8$ hours after surgery; (ii) women with additional VTE risk factors: LMWH, e.g. enoxaparin, $0.5 \mathrm{mg} / \mathrm{kg}$ (e.g. $40 \mathrm{mg}$ ) sc daily until discharge and continuing for 7 days thereafter, beginning 6 - 8 hours after surgery (IPC can be added during hospital stay).

\subsubsection{Recommendation for the treatment of acute cerebral} venous thrombosis ${ }^{[15-17]}$

- There is general consensus that anticoagulation with unfractionated heparin or LMWH is appropriate and sufficient treatment, provided meningitis has been excluded.

- There is insufficient evidence to support the routine use of local or systemic thrombolysis.

- The presence of venous infarction is not a contraindication to anticoagulation.

\subsubsection{General recommendations}

\subsubsection{Monitoring of patients on LMWH}

- The patient's platelet count should be checked on initiation of LMWH, after 5 days, and regularly thereafter while on therapy.

- Anticoagulant activity is measured using an anti-Xa activity assay:

- Anti-Xa measurement is especially indicated in pregnancy, in renal failure and in excessively obese patients in whom large dosages are required.

- The anti-Xa assay must be calibrated for each LMWH tested.

- The anti-Xa assay is currently available for enoxaparin and nadroparin at the Charlotte Maxeke Johannesburg Hospital NHLS haematology laboratory ((011) 488-3068 or (011) 489-8534) as well as in private laboratories.

- A $5 \mathrm{ml}$ sample of citrated blood taken 3 hours after an LMWH dose is required for the assay.

- Target levels for anti-Xa:

- prophylaxis target: 0.3 - 0.5 anti-Xa units $/ \mathrm{ml}$ of blood

- therapeutic target: 0.6 - 1.0 anti-Xa units $/ \mathrm{ml}$ of blood

- target for therapeutic anticoagulation in pregnant patients with an artificial cardiac valve: 1.0 - 1.2 anti-Xa units $/ \mathrm{ml}$ of blood.
1.2.6.2. Measuring drug activity of NOACs (dabigatran and rivaroxaban): ${ }^{[3,14,18]}$

- No routine laboratory monitoring is required.

- Measuring the drug effect may be useful in:

- bleeding

- overdosage

- assessment of compliance

- need for urgent surgery, thrombolysis, or other intervention

- extremes of body weight

- children

- renal insufficiency.

- Suggested assays to measure drug activity of NOACs:

- Rivaroxaban: anti-Xa assay utilising a specific rivaroxaban calibrator

- Dabigatran: diluted thrombin time or ecarin clotting time.

- Routine coagulation assays may also be affected by the NOACs, with dabigatran prolonging the partial thromboplastin time and rivaroxaban affecting the INR.

- Routine coagulation assays should be performed at trough levels of the NOACs, i.e. prior to administration of the next dose.

\subsubsection{Switching between anticoagulation modalities ${ }^{[13,17,18]}$}

Recommendations when switching between standard anticoagulation modalities and NOACs are presented in Table 2.

\subsubsection{Management of bleeding patients ${ }^{[10,12,13,17-20]}$}

- Do not use thromboprophylaxis if there is severe bleeding.

- Discontinue LMWH as well as any other haemostatically active agents that may contribute to haemorrhage.

- Supportive care including transfusion of blood products.

- LMWH:

- Measurement of anti-Xa levels may be indicated.

- Protamine sulfate is effective in neutralising the antithrombin activity of LMWH but has limited effect on the anti-Xa activity. Consider protamine sulphate if bleeding is severe.

- A dose of $1 \mathrm{mg}$ protamine sulphate reverses the effect of 100 anti-Xa units of LMWH ( $1 \mathrm{mg}$ enoxaparin is equivalent to $\sim 100$ anti-Xa units). To reverse the effect of $40 \mathrm{mg}$ enoxaparin, $40 \mathrm{mg}$ protamine sulphate is needed.

- A repeat dose of $0.5 \mathrm{mg}$ of protamine sulphate per $100 \mathrm{anti}-\mathrm{Xa}$ units of enoxaparin is indicated if the patient is still bleeding, and can be repeated to a maximum of 3 doses.

- NOACs (dabigatran and rivaroxaban):

- No specific antidotes are available, but these agents have short durations of action (1.5 - 3 hours) provided renal function is normal.

- Mild/local bleeding: (i) stop NOAC; (ii) apply local compression.

- Severe/life-threatening bleeding: (i) stop NOAC; (ii) apply local compression; (iii) surgery to achieve haemostasis; (iv) supportive measures - fluid therapy, haemodynamic support, transfusion of blood and blood products.

- Other measures: (i) charcoal, in case of suspected overdose; (ii) haemostatic agents: (a) prothrombin complex concentrate and its activated form (PCC and aPCC) - preliminary data suggest that rivaroxaban but not dabigatran can be reversed with these agents, but they should not be administered prophylactically owing to the risk of thrombosis; (b) activated recombinant factor VII (rFVIIa) - consider in the case of emergency bleeding not responding to other measures; (iii) dialysis - dabigatran is dialysable, but rivaroxaban is highly protein bound and therefore not dialysable. 
Table 2. Recommendations when switching between standard anticoagulation modalities and the new oral anticoagulants

\begin{tabular}{|c|c|c|}
\hline & Rivaroxaban & Dabigatran \\
\hline $\begin{array}{l}\text { Switching from parenteral/subcutaneous } \\
\text { anticoagulation to NOACs }\end{array}$ & $\begin{array}{l}\text { Administer rivaroxaban at time scheduled } \\
\text { for and instead of parenteral/subcutaneous } \\
\text { anticoagulation }\end{array}$ & $\begin{array}{l}\text { Administer dabigatran } 0 \text { - } 2 \text { hours before the } \\
\text { next scheduled dose of parenteral/subcutaneous } \\
\text { anticoagulation }\end{array}$ \\
\hline $\begin{array}{l}\text { Switching from NOACs to parenteral/ } \\
\text { subcutaneous anticoagulation }\end{array}$ & $\begin{array}{l}\text { - Administer parenteral/subcutaneous } \\
\text { anticoagulation at the next scheduled and } \\
\text { instead of rivaroxaban dose }\end{array}$ & $\begin{array}{l}\text { - Administer parenteral/subcutaneous } \\
\text { anticoagulation at the next scheduled and instead } \\
\text { of dabigatran dose }\end{array}$ \\
\hline Switching from NOACs to warfarin & $\begin{array}{l}\text { - Simultaneous administration of rivaroxaban } \\
\text { and warfarin until INR }>2.0 \\
\text { - Measure INR } 24 \text { hours after last intake of } \\
\text { rivaroxaban }\end{array}$ & $\begin{array}{l}\text { - Starting warfarin based on } \mathrm{CrCl} \text { : } \\
\text { - } \mathrm{CrCl}>50 \mathrm{ml} / \mathrm{min} \text { : start warfarin } 3 \text { days before } \\
\text { discontinuing dabigatran } \\
\text { - } \mathrm{CrCl} 31-50 \mathrm{ml} / \mathrm{min} \text { : start warfarin } 2 \text { days } \\
\text { before discontinuing dabigatran } \\
\text { - } \mathrm{CrCl} 15-30 \mathrm{ml} / \mathrm{min} \text { : start warfarin } 1 \text { day } \\
\text { before discontinuing Dabigatran. } \\
\text { - } \mathrm{CrCl}<15 \mathrm{ml} / \mathrm{min} \text { : no recommendation } \\
\text { NOTE: } \mathrm{INR} \text { will not reliably reflect the effect of } \\
\text { warfarin until at least } 2 \text { days after discontinuation } \\
\text { of dabigatran }\end{array}$ \\
\hline Switching from warfarin to NOACs & $\begin{array}{l}\text { - In VTE treatment: administer rivaroxaban } \\
\text { when INR }<2.5 \\
\text { - In stroke prevention in AF: administer } \\
\text { rivaroxaban when INR }<3.0\end{array}$ & $\begin{array}{l}\text { - Dabigatran can be administered as soon as INR } \\
\text { is }<2\end{array}$ \\
\hline
\end{tabular}

\section{Treatment of VTE}

\subsection{Initiation of anticoagulation ${ }^{[2,3]}$}

LMWH offers definite advantages over UFH, because not only is the dosing convenient but there is generally no need to monitor patients. This allows for outpatient management for certain patients. It may also result in a reduced risk of recurrence of VTE.

LMWH should be used as follows:

- Enoxaparin $1 \mathrm{mg} / \mathrm{kg} \mathrm{sc}$ twice daily

OR

- Nadroparin weight-adjusted $0.1 \mathrm{ml} / 10 \mathrm{~kg} s \mathrm{sc}$ twice daily

OR

- Dalteparin 100 anti-Xa U/kg sc twice daily.

The above drugs should be given for at least 5 days.

- Warfarin should be started at a dose of $5 \mathrm{mg}$ orally daily from day 2 of anticoagulation. NOTE: The practice of giving a 'loading dose' has been discontinued.

- The INR should be measured 2 - 3 days after starting warfarin and then daily, with dose adjustments to achieve a therapeutic range of 2 - 3 (for most indications).

- LMWH must be given for at least $\mathbf{5}$ days even if the INR has reached the therapeutic level.

- LMWH can be discontinued once the INR has been in the therapeutic range for 2 consecutive days.

- For massive thrombosis or PE, LMWH should be given for 7 - 10 days

- For massive PE, thrombolytic therapy is indicated in the presence of haemodynamic compromise, e.g. recombinant tissue plasminogen activator (r-TPA) $100 \mathrm{mg}$ intravenously over 2 hours.

The NOACs were not registered for the treatment of VTE at the time of publication of this guideline.

\subsection{Duration of oral anticoagulation ${ }^{[9,13,20]}$}

The duration of treatment needs to be individualised according to the patient's thromboembolic risk level, and only basic recommendations are given.

- Patients with reversible or time-limited risk factors should be treated for at least 3 months.

- Patients with idiopathic DVT and all patients with PE should be treated for at least 9 months.

- Patients with idiopathic or recurrent VTE, or continuing risk factors, or who have had a life-threatening event or a thrombosis in an unusual site, will probably benefit from longer duration of anticoagulation, possibly lifelong in some patients depending on their INR control.

- Underlying antithrombin deficiency, antiphospholipid syndrome or malignant disease carry the highest risk of relapse, and lifelong anticoagulation as secondary prophylaxis should be considered in these settings. The presence of multiple concurrent risk factors also significantly increases the risk of recurrence.

- The presence of heterozygous factor V Leiden is a weak independent risk factor for recurrence and is not an indication for long-term anticoagulation following a first event.

- Spontaneous superficial thrombophlebitis: current data suggest intermediate-dose LMWH for 1 month, e.g. enoxaparin $0.5 \mathrm{mg} / \mathrm{kg}$ daily.

\subsection{Venocaval filters ${ }^{[2]}$}

Venacaval filters are indicated in the following situations:

- recurrent VTE despite adequate anticoagulation

- contraindications to anticoagulation such as head injury

- clinical benefit has recently been documented in haemodynamically unstable patients with pulmonary emboli. 


\section{GUIDELINE}

\subsection{Catheter-directed thrombolysis ${ }^{[2]}$}

Catheter-directed thrombolysis may be indicated only in centres with the necessary expertise for selected young patients with a large clot burden in ileo-femoral thrombosis.

\subsection{Thrombophilia screening ${ }^{[21]}$}

The presence of an underlying hereditary thrombophilic state does not alter initial management, and thrombophilia screening should be delayed until 2 weeks after discontinuation of therapy because the results are altered by the acute event and by anticoagulant therapy.

\subsection{Outpatient management ${ }^{[12,22]}$}

Management of VTE in the outpatient setting is safe and costeffective provided that:

- the patient is able to understand and administer therapy himself/herself

- the patient is able to attend regular follow-up and has rapid access to hospital care should it be required

- no complicating factors (for example an increased bleeding risk) are present.

\subsection{Management of non-therapeutic INRs ${ }^{[12,22]}$}

This should be individualised according to bleeding risk. General guidelines are as follows:

- INR $>5$ and $<10$, no significant bleeding:

- omit warfarin

- monitor INR daily until back in therapeutic range

- restart warfarin at lower dose

- consider low-dose oral vitamin $\mathrm{K}$ if INR remains prolonged.

- INR $>10$, no significant bleeding:

- stop warfarin

- give vitamin K 2 mg orally

- monitor INR daily until in therapeutic range (repeat vitamin $\mathrm{K}$ as required)

- restart warfarin at lower dose.

- Significant life-threatening bleeding:

- stop warfarin

- give fresh-frozen plasma at a dose of $15 \mathrm{ml} / \mathrm{kg}$ or prothrombin complex concentrate $(50 \mathrm{U} / \mathrm{kg})$

- administer vitamin K 1 - 2 mg slowly intravenously.

Special precautions should be exercised when reversing anticoagulation in patients with prosthetic heart valves.

\section{References}

1. Caprini JA, Arcelus JI, Reyna JJ. Effective risk stratification of surgical and non-surgical patients for venous thromboembolic disease. Semin Hematol 2001;38(2 suppl 5):12-19.

2. Eight American College of Chest Physicians (ACCP) Consensus Conference on Antithrombotic Therapy. Chest 2008;133(6):1293-1295. [http://dx.doi.org/10.1378/chest.08-0782]

3. Hyers TM, Agnelli G, Hull RD. Antithrombotic therapy for venous thromboembolic disease. Ches 1998;114(5 suppl):561S-578S. http://dx.doi.org/10.1378/chest.114.5_Supplement.561S

4. Mismetti P, Laporte-Simitsidis S. Prevention of venous thromboembolism in internal medicine with unfractionated or low-molecular-weight heparins: A meta-analysis of randomised clinical trials. Thromb Haemost 2000;83:14-19.

5. Pottier P, Planchon B, Truchaud F, Pistorius MA, Furic I, Grolleau JY. Rationalisation of risk factors fo venous thromboembolism in medical inpatients: A prospective study. J Mal Vasc 2000;25(4):241-249. [http://dx.doi.org/10.1097/01.PCC.0000269380.66845.21]

6. Prevention of VTE: International Consensus Statement (guidelines according to scientific evidence). Int Angiol 1997;16:3-38.

7. Samama MM, Cohen AT, Darmon J-Y, et al. A comparison of enoxaparin with placebo for the prevention of venous thromboembolism in acutely ill medical patients. N Engl J Med 1999;341 (11):793 800. [http://dx.doi.org/10.1056/NEJM199909093411103
8. Dahl $\mathrm{OE}$, Bergqvist $\mathrm{D}$. Current controversies in deep vein thrombosis prophylaxis after orthopaedic surgery Curr Opin Pulm Med 2002;8(5):394-397. [http://dx.doi.org/10.1097/00063198-200209000-00009]

9. Hirsch J, Warkentin TE, Shaughnessy SG. Heparin and low-molecular-weight heparin: Mechanisms of action, pharmacokinetics, dosing, monitoring, efficacy, and safety. Chest 2001;119(1 suppl):64S-94S. http://dx.doi.org/10.1378/chest.119.1_suppl.64S]

10. Hull RD, Brant RF, Pineo GF, Stein PD, Raskob GE, Valentine KA. Preoperative vs. postoperative initiation of LMWH prophylaxis against VTE in patients undergoing elective hip replacement. Arch Intern Med 1999;159(2):137-141. [http://dx.doi.org/10.1001/archinte.159.2.137]

11. Kearon C, Gent M, Hirsh J, et al. Comparison of 3 months of anticoagulation with extended anticoagulation for a first episode of idiopathic VTE. N Engl J Med 1999;340(12):901-907. Erratum in: N Engl J Med 1999;341(4):298. [http://dx.doi.org/10.1056/NEJM199903253401201]

12. Prandoni P. Heparins and venous thromboembolism: Current practice and future directions. Thromb Haemost 2001;86:488-498.

3. O'Shea SI, Ortel TL. Issues in the utilisation of low molecular weight heparins. Semin Haematol 2002;39(3):172-178. [http://dx.doi.org/10.1053/shem.2002.34090]

14. van Ryn J, Stangier J, Haertter S, et al. Dabigatran etexilate - a novel, reversible, oral direct thrombin van Ryn J, Stangier J, Haertter S, et al. Dabigatran etexilate - a novel, reversible, oral direct thrombin
inhibitor: interpretation of coagulation assays and reversal of anticoagulant activity. Thromb Haemost 2010:103(6):1116-1127. [http.//dx doi org/10.1160/TH09-11-0758

15. Coutinho JM, Stam J. How to treat cerebral venous and sinus thrombosis. J Thromb Haemost 2010;8(5):877-883. [http://dx.doi.org/10.1111/j.1538-7836.2010.03799.x]

16. Einhäupl K, Stam J, Bousser MG, et al. EFNS guideline on the treatment of cerebralvenous and sinus thrombosis in adult patients. Eur J Neurol 2010;17(10):1229-1235. [http://dx.doi.org/10.1111/j.1468331.2010.03011.x

17. Furie KL, Kasner SE, Adams RJ, et al. Guidelines for the prevention of stroke in patients with stroke or transient ischemic attack: A guideline for healthcare professionals from the American Heart Association/American Stroke Association. Stroke 2011;42(1):227-276. [http://dx.doi.org/10.1161/ STR.0b013e3181f7d043

18. Eerenberg ES, Kamphuisen PW, Sijpkens MK, Meijers JC, Buller HR, Levi M. Reversal of rivaroxaban and dabigatran by prothrombin complex concentrate: A randomized, placebo-controlled, crossover study in healthy subjects. Circulation 2011;124(14):1573-1579. [http://dx.doi.org/10.1161/ CIRCULATIONAHA.111.029017]

19. Lindhoff-Last E, Samama MM, Ortel TL, Weitz JI, Spiro TE. Assays for measuring rivaroxaban: Their suitability and limitations. Ther Drug Monit 2010;32(6):673-679. [http://dx.doi.org/10.1097/ FTD .0b013e3181f2f264]

20. Palareti G. Bleeding complications of oral anticoagulant treatment. Lancet 1996;348(9025):423-428. [http://dx.doi.org/10.1016/S0140-6736(96)01109-9]

21. Walker ID, Greaves M, Preston FE. Guidelines for investigation and management of heritable thrombophilia. Br J Haematol 2001;114(3):512-528. [http://dx.doi.org/10.1046/j.13652141.2001.02981.x]

22. Chai SJ, Macik BG. Improving the safety profile of warfarin. Semin Hematol 2002;39(3):179-186. [http://dx.doi.org/10.1053/shem.2002.34089]

\section{Appendix I. Risk assessment ${ }^{[1]}$}

VTE risk factors can be divided into predisposing factors (i.e. patient characteristics) and exposing factors (i.e. underlying medical conditions, nature of surgical intervention, etc.).

Risk assessment

Predisposing risk factor

Relative risk weighting

Thrombophilia

High

History of VTE

High

Malignancy

High

Drugs, e.g. tuberculosis treatment,

thalidomide

High

HIV infection

High

Auto-immune disease

High

Advanced age ( $>60$ years)

Moderate

Chronic cardiac insufficiency

Moderate

Obesity (BMI $>30 \mathrm{~kg} / \mathrm{m}^{2}$ )

Moderate

Oestrogen therapy

Moderate

Pregnancy and the postpartum period Low

Nephrotic syndrome Low

Varicose veins

Low 


\section{GUIDELINE}

Subcategories of VTE risk in surgical and non-surgical patients ${ }^{[1]}$

\begin{tabular}{lll}
\hline & Surgical patients & Medical patients \\
\hline Low VTE risk & - Surgery lasting $<30$ minutes & - Infection or acute inflammatory diseases without bed rest \\
& - Injuries without or with only minor soft-tissue trauma & - Central venous catheters \\
& - No or only minor additional predisposing risk factors & - No or only minor additional predisposing risk factors \\
Moderate VTE risk & - Surgical procedures of longer duration & - Acute cardiac insufficiency (NYHA III/IV) \\
& - Immobilisation of lower limb with plaster cast & - Acute decompensated COPD without ventilation \\
& - Lower limb arthroscopic procedures. & - Infection or acute inflammatory diseases with bed rest \\
& - No or only minor additional predisposing risk factors & - Malignant disease \\
High VTE risk & - Major surgical procedures for malignancy & - No or only minor additional predisposing risk factors \\
& - Multiple trauma or severe trauma of the spine, vertebra or & - Acute decompensated COPD with ventilation \\
& lower limbs & - Sepsis \\
& - Major orthopaedic surgery, e.g. hip or knee replacement & - ICU patients
\end{tabular}

